\title{
Clinical governance as professional self-reflection: A cross- sectional study assessing the quality of COPD care in German general practice
}

\author{
Stefan Heinmüller ( $\square$ stefan.heinmueller@uk-erlangen.de) \\ Luca Frank \\ Friedrich-Alexander-University Erlangen-Nuremberg, University Hospital Erlangen \\ Anina Höfle \\ Friedrich-Alexander-University Erlangen-Nuremberg, University Hospital Erlangen \\ Michael Langer \\ Friedrich-Alexander-University Erlangen-Nuremberg \\ Korbinian Saggau \\ Friedrich-Alexander-University Erlangen-Nuremberg, University Hospital Erlangen \\ Angela Schedlbauer \\ Friedrich-Alexander-University Erlangen-Nuremberg, University Hospital Erlangen \\ Thomas Kühlein \\ Friedrich-Alexander-University Erlangen-Nuremberg, University Hospital Erlangen
}

Friedrich-Alexander-University Erlangen-Nuremberg, University Hospital Erlangen https://orcid.org/0000-0002-7997-7871

\section{Research article}

Keywords: Clinical Governance Quality of Health Care General Practice Pulmonary Disease, Chronic Obstructive

Posted Date: July 26th, 2019

DOl: https://doi.org/10.21203/rs.2.12002/v1

License: () (1) This work is licensed under a Creative Commons Attribution 4.0 International License. Read Full License 


\section{Abstract}

BACKGROUND In the United Kingdom, a system of clinical governance (CG) which was introduced "top-down" by politics tries to ensure high quality health services. In general practice, the meeting of quality targets was linked to financial incentives causing several negative effects. In Germany CG is not established. We advocate a "bottom-up" CG for German general practice to avoid these negative effects. AIMS To test "bottom-up" CG within a network of general practices (GPN) using chronic obstructive pulmonary disease (COPD) as example disease. As a first step, we wanted to assess the current care quality of the GPN for COPD. Furthermore, feasibility of a care quality assessment through routine data from electronic health records (EHR) should be evaluated. METHODS A cross-sectional study was conducted. Quality indicators (QI) were developed according to COPD guidelines. COPD patients of the GPN $\geq 40$ years were identified. For the determination of QI, data were retrieved from EHR. RESULTS In total, 2568 COPD patients were identified. Their mean age was 67 ( $S D \pm 12)$ years, $49 \%$ were male. Thirty-five percent had a parallel diagnosis of asthma. There was no documentation of any spirometry for $54 \%$ of patients, $29 \%$ had a spirometry within the previous year. An influenza vaccination was administered to $37 \%$ within the preceding twelve months, $12 \%$ received a pneumococcal vaccination in the last six years. Smoking status was documented for $44 \%$ within the last year. Several QI were not assessable. CONCLUSION Care quality assessment by means of EHR data was challenging due to non-standardized documentation. Assessable QI indicated suboptimal COPD care. Our results confirm the need for CG in German general practice and better EHR softwares supporting CG through structured documentation and feedback for GPs. We are planning to proceed with "bottom-up" CG by introducing quality improvement measures within the GPN in answer to this study.

\section{Background}

Clinical governance (CG) was first introduced in the United Kingdom (UK) in 1997 by the newly elected Labour government under Tony Blair. In the white paper "The new NHS: modern, dependable" of the UK Department of Health, CG is described as a "system [...] to ensure that clinical standards are met, and that processes are in place to ensure continuous improvement" of health services [1]. The implementation of CG was prompted by the preceding uncovering of severe deficiencies in the services provided by a pediatric cardiac surgery unit in Bristol (known as "Bristol heart scandal") and a number of other high-profile clinical failures [2]. By now, CG is widely implemented in both general practice and in-patient care in the UK.

Quality assurance in health care is surely to be welcomed. Nevertheless, CG in the UK was imposed as a "top-down" maneuver [3]. In general practice, the attainment of predefined quality marks was linked to financial incentives in the "quality and outcomes framework" (QOF), pushing general practitioners (GPs) to follow suggested therapeutic pathways [4]. As a consequence, some doctors felt deprived of their professional freedom and argued that the QOF created perverse incentives [4]. The QOF was even called a "straitjacket" that prevents doctors from tailoring treatments according to their patients' needs [5]. Moreover, to later be able to demonstrate the achieved quality, a thorough and standardized electronic documentation was necessary for GPs. Many referred to this as "tick-box medicine" [4]. In the end, the QOF contributed to a standardization process in medicine which critics called an inappropriate industrialization of health care [6].

Although CG is widely unknown in Germany, German general practice also experienced a "top-down" tightening of regulations with regard to quality assurance since the turn of the millennium. For example, disease management programs (DMPs) were introduced in 2002 for a number of chronic conditions [7]. DMPs are based in general practice and aim at standardizing care for frequent chronic conditions, thereby improving care quality and reducing health care expenses $[8,9]$. This is sought to be achieved by encouraging at least half-yearly follow-up visits, GP training, patient education, standardized electronic documentation (with performance feedback and benchmarking) and other measures. One cannot help but notice similarities between the DMPs and the QOF. In the end, both initiatives represent a form of intrusion by society into the GPs' professional independence making them accountable for high(er) quality services. This development can be seen as a reaction to a loss of societal confidence in the medical profession [10]. Nevertheless, Germany seems to be at a rather early stage of this process compared to the UK.

The authors of this paper advocate the implementation of CG in German general practice. However, instead of a "top-down" approach we rather aim for a "bottom-up" introduction of CG, i.e. a system of CG that is governed from inside each general practice without involvement of outside administrative bodies. GPs should be interested in implementing "bottom-up" CG in their practices as it is part of their professional duty of self-reflection [11].

After a pilot trial in which we tested "bottom-up" CG within our academic general practice (results will be published elsewhere) we wanted to implement "bottom-up" CG in numerous general practices. As the first condition of interest we selected chronic obstructive 
pulmonary disease (COPD). That is, because COPD care does oftentimes not comply with clinical practice guidelines' (CPG) recommendations [12-17]. Moreover, many are affected: In 2010, around $8 \%$ of the German population suffered from COPD. It is expected that COPD prevalence in Germany will increase to around $10 \%$ by 2030 [18]. COPD is associated with a decrease in quality of life [19], premature death [20] and a high socioeconomic burden [21]. Not least, COPD care is fairly standardized which facilitates quality assessment.

The aim of this study was to assess the current quality of COPD care in a number of German general practices by means of quality indicators (QI), thereby forming the first step in the buildup of "bottom-up" CG. Secondarily, we wanted to evaluate the feasibility of gathering information on COPD care quality from electronic health record (EHR) data.

\section{Methods}

A cross-sectional study design was applied to assess COPD care quality for a number of German general practices.

\section{Practice recruitment}

Instead of recruiting practices individually we approached a network of general practices (GPN) in the region of Franconia. The GPN is managed centrally and comprises numerous general practices. Most importantly, a common EHR software is used and all practices are interconnected electronically. Consequently, it is possible to extract data from all practices of the GPN with just one data retrieval.

\section{Study population}

In large part, our analysis was based on billing codes as used within the German statutory health insurance system. Consequently, only patients insured by a German statutory health insurance (which is the case for around $87 \%$ of the German population [22]) were taken into account.

Only long-term patients with regular practice visits were included to make sure that GPs had had enough time and opportunity to deliver their usual COPD care. It was considered unreasonable to expect a GP to deliver optimal COPD care to a patient who-for example-had missed to keep all follow-up appointments, had not been visiting the GP for years or had only had a single encounter with the practice so far.

Since in Germany patients are not registered with their GP, a definition was needed for a "Iong-term patient with regular practice visits". We decided to apply the following criteria, all three of which had to be fulfilled (Table 1):

- The first doctor-patient contact in a general practice of the GPN had taken place 24 months prior to the date of data extraction or earlier.

- There were at least five doctor-patient contacts to GPs of the GPN.

- At least one doctor-patient contact in a general practice of the GPN had occurred within twelve months before the date of data extraction.

In Germany, coding of all diagnoses with ICD-10-GM is mandatory [23, 24]. Diagnoses have to be coded each quarter of the year anew if the patient is cared for this diagnosis in the respective quarter. A patient was defined as "patient with COPD" if he/she had at least three documented diagnoses of COPD (i.e. an ICD-10-GM-code starting with "J44.") in his/her EHR within 24 months before the date of data extraction (Table 1).

COPD is uncommon in young patients $[25,26]$. Therefore, following several other research projects, only patients aged $\geq 40$ years were included in this study [27-29].

Since established definitions for "long-term patient with regular practice-visits" and/or "COPD-patients" applicable to our study are lacking, the definitions applied were chosen arbitrarily by our researchers. We considered these definitions to be adequate to identify the patient group of interest.

A sample size calculation was not necessary as all patients who fulfilled the inclusion criteria were included. 


\section{Selection of QI}

In this study, COPD care quality was measured by QI. The QI applied were derived from both current CPG recommendations as well as relevant publications [30-40]. CPG and relevant publications had been identified beforehand through a literature search within CPGdatabases, namely the Guidelines International Network (G-I-N), the National Guideline Clearinghouse (NGC), the National Institute for Health and Care Excellence (NICE) and the Scottish Intercollegiate Guidelines Network (SIGN), on PubMed and Google Scholar, and by reference tracking. In a consensus process, the authors of this paper agreed on a set of 18 QI for this study (Table 4, column "QI"). These 18 QI focused on various aspects of COPD management, such as history taking/assessments, diagnostic procedures, therapeutic measures, (tertiary) prevention and the quality of documentation (e.g. the level of detail of ICD-10-GM coding, see Table 2 and QI \#4 in Table 4). Depending on the QI, different time periods were taken into account, i.e. some QI asked whether the respective measure had ever taken place (no time limitation). Other QI only looked at the previous twelve or 24 months (Table 4). In summary, our QI focused primarily on the quality of processes, rather than on the other two established domains of quality, namely the quality of structures and outcomes [41]. For each QI, both absolute and relative frequencies were calculated. Except for one QI (QI \#16, Table 4), all QI were designed in such a way that a lower percentage corresponded to a lower care quality and vice versa (Table 4, column "Percentage"). Since only descriptive statistical methods were used, Microsoft Excel 2010 was sufficient for data processing.

Insert Table 2 here

\section{Data collection}

Data analyses were performed in the administration office of the GPN by the GPN's IT-personnel with the support of our research staff. Since the EHR software of the GPN did not offer sufficient options for data retrieval itself, the GPN's IT-personnel directly accessed the EHR database using SQL (Standardized Query Language). QI were "translated" into electronic SQL queries. These queries were targeted on ICD-10-GM codes for the identification of patients with COPD, the grading of the severity of the disease and the detection of comorbid diseases like asthma. For the assessment of the number of patient-doctor contacts and the identification of performed diagnostic and therapeutic procedures billing codes were used. Information regarding prescribed medication was identified through the Anatomical Therapeutic Chemical (ATC) classification. By applying these search queries, we were able to gain the information needed for the determination of eleven QI (Table 4).

Regarding the remaining seven QI, however, it was not possible to retrieve the respective data via SQL queries because of nonstandardized documentation (items in Table 4 marked "not extractable"). Therefore, we developed an alternative strategy for the evaluation of these remaining QI which was mainly based on a free-text search. For example, to find out whether a GOLD grade had been assigned to COPD patients, the EHR were searched for the term "GOLD". Then, for a random sample of COPD patients in whose EHR the term "GOLD" was found, we checked through a manual screening of their EHR whether a GOLD grade had indeed been assigned and documented. This was necessary because COPD patients could have been identified mistakenly if they had had any other documentation of the word "gold" within their EHR (e.g. "patient was seen by Dr. Goldman"). If that was the case, we specified our search term and made sure that the modified search did not identify these patients anymore.

Also, hybrid searches were applied. That means we combined free-text searches and other search strategies. Smoking status for example was evaluated by searching the EHR for the German terms for "smok*", "tobacco", "cigar*", "pack years", "PY" etc. At the same time, EHR were also searched for the ICD-10-GM code "F17." which stands for "Mental and behavioral disorders due to use of tobacco". As German EHR softwares frequently do not provide entry fields for smoking status, many GPs assign the "F17-diagnosis" to document that the patient is a smoker. Evidently, using the described free-text or hybrid searches, only approximate results can be gained. This must be kept in mind when interpreting these data. Definitions for the free-text based and hybrid searches can be found in the column "Alternative definition of numerator" in Table 5.

\section{Results}

Final data extraction was conducted on January $17^{\text {th }} 2019$. It identified a total of 20,993 long-term patients ( $\geq 40$ years of age) with regular practice visits for the entire GPN. Of these patients, $2,568(12 \%)$ patients fulfilled our COPD criteria (see "Study population" and 


\section{Participating practices}

Since our study might uncover unfavorable results regarding the GPN's quality of COPD care, the GPN wishes to remain anonymous (but name and contact information of the GPN are known to the editors of this journal). Therefore, regarding the characterization of the GPN, only rough figures can be mentioned: The GPN comprises around 25 practices with more than 75 physicians who are either specialized in general practice/general internal medicine in or in vocational GP training. Additionally, a small number of specialists (e.g. gynecologist, gastroenterologist) are employed by the GPN and work in the GPN's practices. However, since this study is meant to evaluate the quality of COPD care within general practice, patients treated exclusively by specialist doctors were not considered. The practices of the GPN are distributed quite evenly among rural, suburban and urban areas in the district of Franconia (Bavaria, Germany).

\section{Patient characteristics}

Investigated patients with COPD ( $\geq 40$ years) had a mean age of 67.2 years and $49 \%$ of them were male. German EHR software systems mostly allow to code a diagnosis either as an acute diagnosis or as a so called long-term diagnosis. COPD was documented as long-term diagnosis for $27 \%$ of COPD patients. Additional to the COPD diagnosis a diagnosis of Asthma could be found for $35 \%$ of COPD patients. For $25 \%$ of patients with COPD an ICD-10-GM code (German Modification of the $10^{\text {th }}$ revision of the International Statistical Classification of Diseases and Related Health Problems) for exacerbation was documented at least once within the previous 24 months. (Table 3)

Insert Table 3 here

\section{Outcomes for QI}

Numerical data allowing for the calculation of the QI were available for eleven of the 18 QI (Table 4): For 1,182 (46\%) of the 2,568 patients with COPD a billing code of a spirometry could be found in their EHR (ever, i.e. no time limits applied), 756 (29\%) had a spirometry performed within the last twelve months (QI \#2 and \#3, Table 4). A specific ICD-10-GM diagnosis for COPD that takes the FEV1-value of a previous spirometry into account (see example in table caption of Table 2) was found in 735 (29\%) COPD patients (QI \#4). Enrolment in the DMP for COPD and regular appearance for follow-up visits was documented for 776 (30\%) patients with COPD (QI \#6). Within the preceding twelve months, 951 (37\%) COPD patients had received at least one influenza vaccination (QI \#7). At least one pneumococcal vaccination had been administered to 318 (12\%) COPD patients within the previous six years (QI \#8). Inhaled medication (irrespective of the sort of drug and the number of prescriptions) was prescribed to $1,029(40 \%)$ patients with COPD in the preceding 12 months (QI \#14). If the definition is transferred to bronchodilators only (instead of any inhaled medication) it applies to 990 (39\%) COPD patients (QI \#15). Within the time period of twelve months prior to data extraction, 599 (23\%) of COPD patients had at least one prescription of an inhaled corticosteroid (ICS) or another inhaled drug which contained an ICS (Note: For this QI \#16, a higher percentage does not correspond to a higher quality of care). A new documentation or an update of the medication scheme (corresponding to a medication review) could be found in the EHR of 1,238 (44\%) COPD patients in the preceding year (QI \#17). Of the 2,568 patients with COPD, $9(<1 \%)$ had ever taken part in a patient education program on COPD (QI \#18).

Insert Table 4 here

For the remaining seven QI, alternative definitions based on free-text searches or hybrid searches were developed in order to gain at least approximate results (see section "Data collection and analysis" and Table 5). Nevertheless, using this alternative approach, we were only able to obtain numerical values for four of the seven remaining QI. No results could be achieved for the QI "COPD confirmed by post-bronchodilator spirometry" (QI \#1), "Smoking cessation advice" (QI \#10) and "Assessment of inhaler technique" (QI \#11) (Table 4 and Table 5). Of the 2,568 patients with COPD, 55 (2\%) had some form of GOLD grade (grading according to the CPG of the Global Initiative for Chronic Obstructive Lung Disease [33]) documentation in their EHR (ever, i.e. no time limits applied) (QI \#5). The QI for the documentation of smoking status could be found for 1,118 (44\%) of the 2,568 patients with COPD within the previous twelve months (QI \#9). The body mass index (BMI) or a combination of height and weight (allowing for the post hoc calculation of the BMI) was documented for 156 (6\%) of COPD patients in the last year (QI \#12). Text sections within the EHR indicating that an assessment of 
COPD symptom severity was conducted using mMRC or CAT were found for $1(<1 \%)$ COPD patient in the previous twelve months (QI \#13).

Insert Table 5 here

\section{Discussion}

\section{Main findings}

Because of shortcomings in the documentation, assessment of QI was challenging. Despite the additional application of alternative search queries, three of 18 QI (17\%) could not be determined. The remaining 15 QI indicated insufficient performance in COPD care. Overall, the EHR software did not adequately support standardized documentation and care quality assessments.

\section{Do we measure quality of care or quality of documentation?}

The primary objective of this study was to measure the quality of COPD care by gathering data to assess QI. Secondarily, overall feasibility of quality of care assessments by means of routine EHR data should be evaluated. A fundamental requirement for the retrieval of data reflecting care quality is a thorough and standardized documentation. Shortcomings in the documentation made the gathering of data challenging. Therefore, especially for the second attempt of data retrieval which was based on free-text/hybrid searches, data need to be interpreted cautiously. Reasons for poor documentation are diverse: Procedures may have been forgotten orif performed-may not be documented properly. Even if documented, this mostly occurs in a narrative free-text, making this information hard to retrieve later. Also, non-standardized documentation is prone to incompleteness: Health personnel either forget to document pieces of information or even willingly document in an abbreviated and fragmented manner (frequently with typing errors) as they tend to perceive the obligatory documentation as a time-consuming barrier in their genuine work, namely treating patients [42].

Overall, it seems that documentation in German EHR is just an electronic echo of paper based records without taking advantage of the potentials offered by computers. As a result, it is difficult if not impossible to reproduce from EHR what happened during consultations. If information on a specific procedure is missing, researchers have to treat that procedure as if it hadn't been performed at all. In most cases, EHR softwares offer very limited possibilities of analyzing routine data themselves. And even if data analysis was possible, doctors would need support from IT-personnel to execute electronic searches.

Summing up, we wanted to appraise the quality of COPD care using QI but were in part unable to do so because of fragmented and non-standardized documentation.

As described by Balgrosky, "[i]nformation emanating from [...] data sources is only as good as the quality and integrity of the data" [43]. Consequently, for practicing CG, it is crucial to improve the quality of documentation. Otherwise, future evaluations of care quality will face the same obstacles.

Other studies reported similar problems: Kaufmann et al. found gaps in the documentation of COPD measures in Swiss general practice and concluded that bridging these gaps is central [17]. Poor and incomplete data collection in EHR was also observed in Italian general practice by Bertella et al. trying to evaluate quality of COPD care [13]. The Austrian IQuaB-project (Improving Quality by Benchmarking) faced similar barriers. Problem areas involved plurality in EHR softwares, diverse and missing EHR software functions, unstructured databases and limited data extraction options $[44,45]$. Consequently, when looking at reasons for poor data quality it comes down to insufficient EHR softwares. The underlying reason for this is probably the fact that they were originally introduced for billing purposes only, not CG.

\section{Interpretation of findings in relation to previously published work}

Despite the barriers in the data collection we gained absolute and relative frequencies for 15 of $18 \mathrm{QI}$. In the following, we will focus on QI considered specifically important. These items will be compared to performance measures from other countries.

For the diagnosis of COPD, spirometry is mandatory [33]. Moreover, for patients with confirmed COPD, spirometry is recommended to be repeated yearly [33]. However, the proportion of patients in our study who ever had a spirometry documented was only $46 \%$. This finding 
does not seem to be limited to Germany: International studies report the proportion of COPD patients in general practice with a spirometry recorded in their EHR (ever) to be at $11.7 \%$ for Austria [44] and $60.9 \%$ for Italy [34].

In our study spirometry had been performed on $29 \%$ of COPD patients within the preceding twelve months. Another study conducted by Belletti et al. in general practice in the US reported a documented spirometry for 35.5\% of COPD patients in the preceding year [16]. For Switzerland, Kaufmann et al. report that spirometry had been performed on 51\% of COPD patients in the previous twelve months [17].

To treat a COPD patient in accordance with current CPG, a classification of disease severity and its subsequent documentation is necessary (e.g. GOLD grades 1-4 and A-D) [33]. That is, because medication mostly depends on the grade of disease severity. Other studies found documentation of GOLD grades in the EHR of $48 \%$ (US) [16] and 72\% (Switzerland) [17] of COPD patients in general practice. In our study, information on a GOLD grade were found for only $2 \%$ of COPD patients which surprised us as GOLD grades were proposed in the German National CPG on COPD as early as 2006 [30]. Paradoxically, the ICD-10-GM classification of COPD severity (Table 2) which by law needs to be applied in Germany for the coding of diagnoses uses different FEV1 cut-off values than the GOLD classification. Therefore, one may argue that a different, not necessarily worse classification scheme is applied. Nevertheless, we found only $29 \%$ of COPD patients to be classified for disease severity within ICD-10-GM (QI \#4, Table 4). The German DMP for COPD includes mandatory electronic documentation which asks for the latest FEV1 value but strangely not for a disease severity grade. By not asking for the COPD severity grade the DMP does not sufficiently support adequate grade-adjusted prescribing. At the same time numerous less relevant items such as blood pressure, whether the patient wants to receive information regarding a healthy diet and whether the risk of osteoporosis has been evaluated have to be enquired. It seems like the German DMP could put a stronger emphasis on the core areas of COPD management. Since DMP are carried out in almost all general practices in Germany, the overall impact of COPD disease severity grades being included in the DMP protocol would most likely be considerable.

Several CPG recommend yearly influenza vaccinations for COPD patients $[30,46]$ since it can prevent exacerbations and reduce hospitalization [47]. Of the COPD patients investigated in our study $37 \%$ had received an influenza vaccination in the previous twelve months. Other countries seem to achieve better vaccination coverage: Italian general practice patients with COPD had an influenza vaccination rate of $44.2 \%$ in 2011 [34]. In a Swiss study published in $2015,49 \%$ of general practice patients with COPD were reported to have had an influenza vaccination within the preceding twelve months [17]. In the Welsh primary care audit 2015-17, the proportion of patients with COPD having had an influenza vaccination in the preceding influenza season was reported to be $66.0 \%$ [48].

Smoking cessation has the greatest potential to slow down the course of COPD [33, 49]. An essential prerequisite for the delivery of smoking cessation counselling is the knowledge of the patients' present smoking status. The extraction of this information from the patients' EHR in this study was challenging as the documentation of smoking status mostly occurred in a narrative free-text form. The reason behind this is that many German EHR softwares lack an entry field for the documentation of smoking status which we find remarkable. In our study, approximately $44 \%$ of COPD patients had a documentation of smoking status in their EHR within the last year. In other countries, the enquiry and documentation of the patients' smoking status seems to be better: For $77.4 \%$ of Welsh COPD patients, a smoking status had been documented in the preceding 15 months [48]. In a Danish study, information on the present smoking status was found for $92.1 \%$ of COPD patients in general practice [12]. A Swiss study reported that smoking status was documented for $95 \%$ of COPD patients treated in general practice within a twelve months period [17].

In our study, $23 \%$ of COPD patients received an ICS within the last year. As we were not able to assess the patients' disease severity grade it was not possible to determine whether ICS treatment in these patients was adequate. However, we assume that many study patients are over- or undertreated with regard to ICS therapy as shown in another recently published German study on COPD [50]. This study concluded that "two thirds of German COPD patients received an ICS which, however, was not indicated in about half of these cases according to the latest international treatment recommendations."

\section{Strengths and limitations of this study}

To our knowledge, this is the first study in Germany that used a large number of routinely collected data from EHR for the evaluation of COPD care quality in general practice. Had we not applied routine data but questionnaires or standardized examinations instead, we would most likely have achieved more thorough data. Nevertheless, these data would probably have given a misleading picture of both the documentation and care quality for COPD. Another strength can be seen in the fact that we applied strict inclusion criteria: Only COPD patients who had been treated long-term within the GPN were considered. Moreover, the large number of 2,568 COPD patients is an advantage. 
However, there are also a number of limitations. First of all, we were only able to analyze what was documented. Documentation may be incomplete or incorrect. It is important to acknowledge that missing documentation is not equal to low performance. Apart from shortcomings in the documentation we were faced with restrictions in data extraction caused by poor software function which we were able to bypass by directly accessing the underlying EHR database using SQL queries. Especially for COPD patients enrolled in the German DMP for COPD, data extraction was problematic. Electronic searches conducted through the practice software could not access information that had been put into the electronic DMP form which has to be filled out by the GP after a DMP consultation. That is, because the DMP form is embedded in an application outside the regular EHR software. The fact that this information could not be taken into account clearly is a limitation. Nevertheless, GPs face these obstacles every day and the barriers experienced in this study reflect real-life situations. A further weakness may be the limited generalizability of our results. Not only did we analyze general practices from just one region but these general practices were also connected as they are all part of the same GPN. Moreover, GPs of the GPN are employed whereas usually, GPs in Germany are self-employed. This may have influenced our results. Nevertheless, we judge that our results are somewhat representative of an average general practice in Germany. It also needs to be pointed out that in Germany patients do not necessarily need a referral from their GP to seek specialist care. Without referral, however, the patients' GP does oftentimes not receive a medical report from the specialist. In these cases, the results of the encounter with the specialist can consequently not be found in the patients' EHR. Even if specialist reports were sent to the GP, these are saved as scanned PDF-files the contents of which are not searchable by the EHR software. The same accounts for medical reports from hospitals. Thus, some procedures (e.g. spirometry) may have been performed more often than reported in this study. Another limitation is the lacking possibility of evaluating COPD patients' medication with regard to CPG conformity. That is, because CPG recommend drugs based on disease severity classifications, which were not assigned to most COPD patients in this study. A final limitation may be the fact that we were not able to identify patients with Asthma-COPD overlap Syndrome (ACOS) for which an ICS therapy may be reasonable. Consequently, the numbers determined in this study for ICS therapy ( $23 \%$ and $28 \%$, Table 4$)$ may overestimate the real value within the sub-group of patients suffering solely from COPD (not Asthma or ACOS).

\section{Implications for the future research, policy and practice}

The most important tool in practicing CG seems to be a well-designed EHR software. In our view, such a software that contains electronic review forms for routine encounters and allows users to modify or newly build them is an essential prerequisite for practicing "bottom-up" CG. These review forms would structure the consultation and could allow for some tasks to be delegated to nurses or health care assistants, thereby unburdening GPs. A review form can also act as a reminder ("checklist") thus contributing to a higher quality care by not letting the medical staff forget important care processes. Not least, review forms can be seen as a simple tool for documentation. Also, data entry fields within review forms should contain underlying codes for classification (such as "Read Codes" or "SNOMED" in the UK). That way, data generation for both feedback to the practice team as well as research would be carried out along the way. On a regular basis, the EHR software should provide feedback reports for the practice team enabling them to identify and resolve areas of suboptimal care. In short, an EHR software that supports CG is needed for German general practice.

Subsequent to this study, its results will be presented to the GPs of the GPN in order to give them feedback on the quality of care they deliver. After that, we are planning to develop and test a structured electronic review form (as described in the previous paragraph) together with GPs from the GPN. Thereby we want to contribute to the setup of a sustainable system of CG in German general practice.

\section{Conclusions}

Non-standardized and incomplete documentation in EHR of German general practice patients with COPD caused challenging data extraction processes and consequently some degree of uncertainty regarding our findings. Nevertheless, it seems beyond question that major deviations between recommended and actual COPD care exist in German general practice. Our findings highlight the need for better EHR softwares that contribute to both an improved COPD management and a better electronic documentation in German general practice. We are planning to proceed with "bottom-up" CG by introducing quality improvement measures within the GPN in answer to this study.

\section{Abbreviations}

ACOSAsthma-COPD-overlap-syndrome 
ATCAnatomical Therapeutic Chemical Classification System

BMIBody mass index

CATCOPD assessment test

CGClinical governance

COPDChronic obstructive pulmonary disease

CPGClinical practice guideline

DMPDisease management program

EHRElectronic health records

FAUFriedrich-Alexander-University Erlangen-Nuremberg

FEV1Forced expiratory volume in 1 second

G-I-NGuidelines International Network

GOLDGlobal Initiative for Chronic Obstructive Lung Disease

GPGeneral practitioner

GPNGeneral practice network

ICD-10-GM10th revision of the International Statistical Classification of Diseases and Related Health Problems, German Modification

ICSInhaled Corticosteroid

mMRCmodified Medical Research Council

NGCNational Guideline Clearinghouse

NHSNational Health Service

NICENational Institute for Care and Health Excellence

PYPack years

QIQuality indicator

QOFQuality and Outcomes Framework

SDStandard deviation

SIGNScottish Intercollegiate Guidelines Network

SNOMEDSystematized Nomenclature of Medicine

SQLStandardized Query Language

UKUnited Kingdom

Declarations

Ethics approval and consent to participate

Page 9/15 
German law allows the analysis of patient data for quality monitoring within practices and for research purposes in case they are anonymized. Therefore, our research team merely offered the search queries and received only pooled data from the GPN. The Ethics Committee of the Medical Faculty at the Friedrich-Alexander-University of Erlangen-Nuremberg (FAU) approved our study protocol (registration number "124_18 Bc").

\section{Consent for publication}

Not applicable.

\section{Availability of data and material}

In accordance with the ethical approval, the authors received only aggregated and anonymized data all of which are reported in this article. No additional data are available. Applied search queries on SQL basis are available from the corresponding author.

\section{Competing interests}

SH, LF, AH, KS, AS and TK declare no competing interests. ML is both a doctoral candidate at our Institute of General Practice and an ITspecialist employed by the GPN. Therefore, ML could hypothetically have influenced the data presented in this work. Aside from that ML declares no competing interests.

\section{Funding}

The study was funded through the regular budget of the Institute of General Practice (Universitätsklinikum Erlangen, Erlangen, Germany).

\section{Authors' contributions}

$\mathrm{SH}, \mathrm{AS}$ and TK conceived and designed the study. SH conducted the literature search. $\mathrm{SH}, \mathrm{AH}, \mathrm{KS}$ and $\mathrm{ML}$ extracted, analyzed and interpreted the data. SH wrote the manuscript. TK, AS and LF revised the manuscript. All authors read and approved the final version of the manuscript.

\section{Acknowledgements}

The authors want to thank the GPN which wishes to remain anonymous as well as its IT-personnel for the good cooperation.

\section{References}

1.The Department of Health. The New NHS: modern, dependable. 1997.

https://assets.publishing.service.gov.uk/government/uploads/system/uploads/attachment_data/file/266003/newnhs.pdf. Accessed 19 May 2019.

2.Scally G. Deaths in Bristol have changed the face of British medicine. CMAJ. 2001;165:628.

3.Campbell SM, Sheaff R, Sibbald B, Marshal MN, Pickard S, Gask L, et al. Implementing clinical governance in English primary care groups/trusts: reconciling quality improvement and quality assurance. Qual Saf Health Care. 2002;11:9-14.

4.McCartney M. The great QOF experiment. BMJ. 2016;353:1763.

5.Whitaker P. The NHS is Britain's beating heart-don't let it flatline. NewStatesman. 2011.

https://www.newstatesman.com/health/2011/02/nhs-care-patients-service. Accessed 19 May 2019.

6.Iliffe S. From General Practice to Primary Care: The industrialization of family medicine. Oxford: Oxford University Press; 2008.

Page $10 / 15$ 
7.Linder R, Horenkamp-Sonntag D, Engel S, Köppel D, Heilmann T, Verheyen F. Validität der ärztlichen Dokumentation von Disease Management Programmen. Dtsch Med Wochenschr. 2014;139:19-22.

8.Mehring M, Donnachie E, Fexer J, Hofmann F, Schneider A. Disease management programs for patients with COPD in Germany: a longitudinal evaluation of routinely collected patient records. Respir Care. 2014;59:1123-1132.

9.Achelrod D, Welte T, Schreyögg J, Stargardt T. Costs and outcomes of the German disease management programme (DMP) for chronic obstructive pulmonary disease (COPD)-A large population-based cohort study. Health Policy. 2016;120:1029-1039.

10.Timmermans S, Kolker ES. Evidence-based medicine and the reconfiguration of medical knowledge. J Health Soc Behav. 2004;45 Suppl:177-193.

11.Kuehlein T, Carvalho A, Viegas Dias C, Rodrigeus D, Pinto D. How do I care for my patients with. J Health Sci (El Monte). 2015;3:141147.

12.Lange P, Rasmussen FV, Borgeskov H, Dollerup J, Jensen MS, Roslind K, et al. The quality of COPD care in general practice in Denmark: the KVASIMODO study. Prim Care Respir J. 2017;16;174-181.

13.Bertella E, Zadra A, Vitacca M. COPD management in primary care: is an educational plan for GPs useful? Multidiscip Respir Med. 2013;8:24.

14.Weidinger P, Nilsson JL, Lindblad U. Adherence to diagnostic guidelines and quality indicators in asthma and COPD in Swedish primary care. Pharmacoepidemiol Drug Saf. 2009;18:393-400.

15.Bourbeau J, Sebaldt RJ, Day A, Bouchard J, Kaplan A, Hernandez P, et al. Practice patterns in the management of chronic obstructive pulmonary disease in primary practice: the CAGE study. Can Respir J. 2008;15:13-19.

16.Belletti D, Liu J, Zacker C, Wogen J. Results of the CAPPS: COPD-Assessment of Practice in Primary Care Study. Curr Med Res Opin. 2013;29:957-966.

17.Kaufmann C, Markun S, Hasler S, Dalla Lana K, Rosemann T, Senn O, et al. Performance Measures in the Management of Chronic Obstructive Pulmonary Disease in Primary Care-A Retrospective Analysis. Praxis (Bern 1994). 2015;104:897-907.

18.Pritzkuleit R, Beske F, Katalinic A. [Disease numbers in pneumology-a projection to 2060]. Pneumologie. 2010;64:535-540.

19.Wacker ME, Jörres RA, Karch A, Wilke S, Heinrich J, Karrasch S, et al. Assessing health-related quality of life in COPD: comparing generic and disease-specific instruments with focus on comorbidities. BMC Pulm Med. 2016;16:70.

20.Gudmundsson G, Gislason T, Lindberg E, Hallin R, Ulrik CS, Brondum E, et al. Mortality in COPD patients discharged from hospital: the role of treatment and co-morbidity. Respir Res. 2006;7:109.

21.Wacker ME, Jorres RA, Schulz H, Heinrich J, Karrasch S, Karch A, et al. Direct and indirect costs of COPD and its comorbidities: Results from the German COSYCONET study. Respir Med. 2016;111:39-46.

22.Institute for Quality and Efficiency in Health Care (IQWiG). Health care in Germany: Health insurance in Germany. 2015. https://www.ncbi.nlm.nih.gov/books/NBK298832. Accessed 19 May 2019.

23.German Institute for Medical Documentation and Information (DIMDI). International Statistical Classification of Diseases and Related Health Problems. 10 ${ }^{\text {th }}$ revision. German Modification. Version 2018. 2018. https://www.dimdi.de/static/de/klassifikationen/icd/icd-10-gm/kode-suche/htmlgm2018/. Accessed 19 May 2019.

24.Sozialgesetzbuch (SGB) Fünftes Buch (V) - Gesetzliche Krankenversicherung. § 295 Abrechnung ärztlicher Leistungen. 1988. https://www.gesetze-im-internet.de/sgb_5/_295.html. Accessed 19 May 2019.

25.Vanfleteren LEGW, Kocks JWH, Stone IS, Breyer-Kohansal R, Greulich T, Lacedonia D, et al. Moving from the Oslerian paradigm to the post-genomic era: are asthma and COPD outdated terms?. Thorax. 2014;69:72-79. 
26.Snell N, Strachan D, Hubbard R, Gibson J, Gruffydd-Jones K, Jarrold I. Epidemiology of Chronic Obstructive Pulmonary Disease (COPD) in the UK: Findings from the British Lung Foundation's 'Respiratory Health of the Nation' Project. Thorax. 2016;71:A20.

27.Bednarek M, Maciejewski J, Wozniak M, Kuca P, Zielinski J. Prevalence, severity and underdiagnosis of COPD in the primary care setting. Thorax. 2016;63:402-407.

28.Raluy-Callado M, Lambrelli D, MacLachlan S, Khalid JM. Epidemiology, severity, and treatment of chronic obstructive pulmonary disease in the United Kingdom by GOLD 2013. Int J Chron Obstruct Pulmon Dis. 2015;10:925-937.

29.Weiss G, Steinacher I, Lamprecht B, Schirnhofer L, Kaiser B, Sonnichsen A, et al. Detection of chronic obstructive pulmonary disease in primary care in Salzburg, Austria: findings from the real world. Respiration. 2014;87:136-143.

30.Bundesärztekammer (BÄK), Kassenärztliche Bundesvereinigung (KBV), Arbeitsgemeinschaft der Wissenschaftlichen Medizinischen Fachgesellschaften (AWMF). Nationale VersorgungsLeitlinie COPD-Langfassung, Version 1.9. 2012.

https://www.leitlinien.de/mdb/downloads/nvl/copd/archiv/copd-vers1.9-lang.pdf. Accessed 19 May 2019.

31.National Institute for Health and Care Excellence (NICE). Chronic Obstructive Pulmonary Disease in Over 16s: Diagnosis and Management (CG101). 2015. http://www.nice.org.uk/guidance/cg101. Accessed 19 May 2019.

32.Schneider A, Tilemann L, Kaufmann-Kolle P. Asthma/COPD. In: Szecsenyi J, Broge B, Stock J, editors. QISA-Das Qualitätsindikatorensystem für die ambulante Versorgung. Berlin: KomPart Verlagsgesellschaft; 2009.

33.Global Initiative for Chronic Obstructive Lung Disease (GOLD). Global Strategy for the Diagnosis, Management, and Prevention of Chronic Obstructive Pulmonary Disease. 2018. https://goldcopd.org/wp-content/uploads/2017/11/GOLD-2018-v6.0-FINAL-revised20-Nov_WMS.pdf. Accessed 19 May 2019.

34.Atella V, Bianchini E, Brignoli O, Cricelli C, Cricelli I, Lapi F, et al. VII Report Health Search. Societá Italiana Medicina Generale. 2012. https://healthsearch.it/documenti/Archivio/Report/VIIReport_2011-2012/VII Report HS.pdf. Accessed 19 May 2019.

35.National Institute for Health and Care Excellence (NICE). The NICE menu of general practice and clinical commissioning group indicators. 2017. https://www.nice.org.uk/Media/Default/Standards-and-indicators/indicator-menu-update.pdf. Accessed 19 May 2019.

36.Kleerup E. Quality indicators for the care of chronic obstructive pulmonary disease in vulnerable elders. J Am Geriatr Soc. 2017;55 Suppl 2:270-276.

37.Prosser T, Bollmeier S. Asthma and COPD. In: Murphy JE, Lee MWL, editors. Pulmonary and Emergency Medicine. American College of Clinical Pharmacy. 2017. https://www.accp.com/docs/bookstore/psap/p2017b2_sample.pdf. Accessed 19 May 2019.

38.Anderson B, Brown H, Bruhl E, Bryant K, Burres H, Conner K, et al. Health Care Guideline: Diagnosis and Management of Chronic Obstructive Pulmonary Disease (COPD). Institute for Clinical Systems Improvement. 2016. https://www.icsi.org/wpcontent/uploads/2019/01/COPD.pdf. Accessed 19 May 2019.

39.Qaseem A, Hopkins R, Kutty K, Persell S, Baker D. Management of Chronic Obstructive Pulmonary Disease: Review of the Performance Measures by the Performance Measurement Committee of the American College of Physicians. American College of Physicians. 2014.

https://www.acponline.org/system/files/documents/clinical_information/performance_measurement/measures/pmc_copd_review.pdf. Accessed 19 May 2019.

40. Health Quality Ontario (HQO). Quality Standards: Chronic Obstructive Pulmonary Disease-Care in the Community for Adults. 2018. https://hqontario.ca/Portals/0/documents/evidence/quality-standards/qs-chronic-obstructive-pulmonary-disease-quality-standarden.pdf. Accessed 19 May 2019.

41.Donabedian A. Evaluating the Quality of Medical Care. Milbank Q. 2005;83:691-729.

42.Miller RH, Sim I. Physicians' use of electronic medical records: barriers and solutions. Health Aff (Millwood). 2004;23:116-126.

Page $12 / 15$ 
43.Balgrosky JA. Essentials of Health Information Systems and Technology. Burlington, MA: Jones \& Bartlett Learning; 2015.

44.Mahlknecht A, Abuzahra ME, Piccoliori G, Enthaler N, Engl A, Sönnichsen A. Improving quality of care in general practices by selfaudit, benchmarking and quality circles. Wien Klin Wochenschr. 2016;128:706-718.

45.Abuzahra M, Mahlknecht A, Piccoliori G, Flamm M, Sönnichsen A. Benchmarking mittels Qualitätsindikatoren in der Hausarztpraxis. Qualitas. 2014;3:10-13.

46.National Institute for Health and Care Excellence (NICE). Indicators for the NICE menu for the QOF, Indicator NM106: The percentage of patients with COPD who have had influenza immunisation in the preceding 1 August to 31 March. 2015.

https://www.nice.org.uk/Media/Default/Standards-and-Indicators/QOF\%20Indicator\%20Key\%20documents/nm106-copdguidance\%20.pdf. Accessed 19 May 2019.

47.Poole PJ, Chacko E, Wood-Baker RW, Cates CJ. Influenza vaccine for patients with chronic obstructive pulmonary disease. Cochrane Database Syst Rev. 2006;1:CD002733.

48.Baxter N, McMillan V, Holzhauer-Barrie J, Robinson S, Stone P, Quint J, et al. Planning for every breath. National Chronic Obstructive Pulmonary Disease (COPD) Audit Programme: Primary care audit (Wales) 2015-17. Data analysis and methodology. Royal College of Physicians. 2017. https://www.rcplondon.ac.uk/file/8468/download?token = dJEwJW2K. Accessed 19 May 2019.

49.van Eerd EA, van der Meer RM, van Schayck OC, Kotz D. Smoking cessation for people with chronic obstructive pulmonary disease. Cochrane Database Syst Rev. 2016;8:CD010744.

50.Graf J, Jorres RA, Lucke T, Nowak D, Vogelmeier CF, Ficker JH. Medical Treatment of COPD. Dtsch Arztebl Int. 2018;155:599-605.

\section{Tables}

Table 1: Definition for a long-term patient with regular practice-visits, definition for a patient with COPD

\begin{tabular}{|c|c|}
\hline Definition for a long-term patient with regular practice visits & Definition for a patient with COPD \\
\hline $\begin{array}{ll}\text { - } & \geq 40 \text { years of age } \\
\text { - } & \text { insured with a German statutory health insurance } \\
\text { - } & \text { first patient-doctor contact in a general practice of the GPN } \geq 24 \\
& \text { months prior to the date of data extraction } \\
\text { - } & \geq 5 \text { patient-doctor contacts to GPs from the GPN } \\
\text { - } & \geq 1 \text { patient-doctor contact in a general practice of the GPN within } \\
& 12 \text { months before the date of data extraction }\end{array}$ & $\begin{array}{l}-\quad \geq 40 \text { years of age } \\
-\quad \geq 3 \text { documentations of a COPD diagnosis (i.e. an ICD-10-GM-code starting with } \\
\text { "J44.") within } 24 \text { months before the date of data extraction }\end{array}$ \\
\hline
\end{tabular}

Table 2: Descriptions of ICD-10-GM diagnoses for COPD with FEV1 values

\begin{tabular}{|c|c|c|c|}
\hline $\begin{array}{l}\text { ICD-10-GM- } \\
\text { code }\end{array}$ & Definition & $\begin{array}{l}\text { additional digit for ICD-10-GM-code specifying degree of } \\
\text { COPD }\end{array}$ & $\begin{array}{c}\text { FEV1 } \\
\text { (\% predicted) } \\
\end{array}$ \\
\hline $\mathrm{J} 44.0$ & $\begin{array}{l}\text { Chronic obstructive pulmonary disease with acute lower respiratory } \\
\text { infection }\end{array}$ & 0 & $<35 \%$ \\
\hline $\mathrm{J} 44.1$ & $\begin{array}{l}\text { Chronic obstructive pulmonary disease with acute exacerbation, } \\
\text { unspecified }\end{array}$ & 1 & $\begin{array}{l}\geq 35 \% \text { but } \\
\quad<50 \%\end{array}$ \\
\hline $\mathrm{J} 44.8$ & Other specified chronic obstructive pulmonary disease & 2 & $\begin{array}{l}\geq 50 \% \text { but } \\
<70 \%\end{array}$ \\
\hline $\mathrm{J} 44.9$ & Chronic obstructive pulmonary disease, unspecified & 3 & $\geq 70 \%$ \\
\hline
\end{tabular}

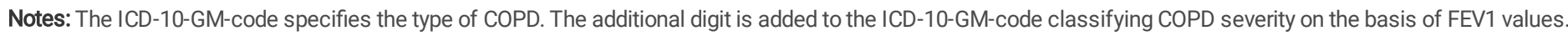

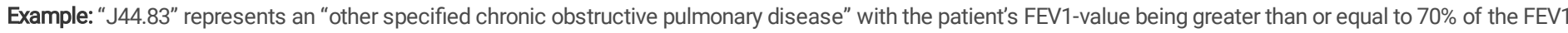
predicted. Consequently, this code can only be assigned if the patients' current FEV1 value is known.

Table 3: Characteristics of COPD patients $\geq 40$ years 


\begin{tabular}{|l|c|}
\hline Characteristics & all patients $\geq 40$ years with COPD $(n=2568)$ \\
\hline Mean $(S D)$ age (in years) & $67.2(12.3)$ \\
\hline Male sex & $1262(49 \%)$ \\
\hline COPD documented as long-term diagnosis & $705(27 \%)$ \\
\hline Parallel diagnosis of Asthma* & $886(35 \%)$ \\
\hline ICD-10-GM-code for a COPD exacerbation documented within the last 24 months** & $631(25 \%)$ \\
\hline
\end{tabular}

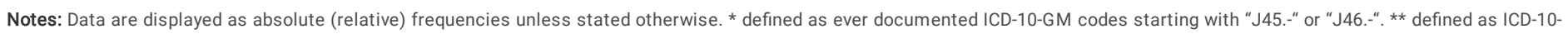
GM codes J44.1-", "J44.10", "J44.11", “J44.12", "J44.13" or “J44.19".

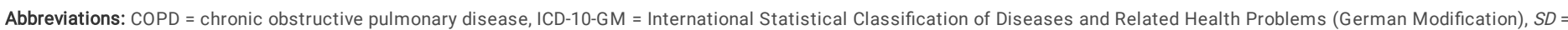
standard deviation

\section{Table 4: QI for COPD}

\begin{tabular}{|c|c|c|c|c|}
\hline$\#$ & QI & Definition of numerator* & $\begin{array}{c}\text { Value of } \\
\text { numerator* }\end{array}$ & Percentage+ \\
\hline 1 & $\begin{array}{l}\text { COPD confirmed by PBD } \\
\text { spirometry }\end{array}$ & all patients with $C O P D \geq 40$ years with at least one documentation of post-bronchodilator spirometry (ever) & \multicolumn{2}{|c|}{ not extractable } \\
\hline 2 & Ever spirometry & all patients with COPD $\geq 40$ years with at least one documented billing code for spirometry (ever) & 1182 & $46 \%$ \\
\hline 3 & Recent spirometry & $\begin{array}{l}\text { all patients with } C O P D \geq 40 \text { years with a billing code for spirometry documented at least once within the last } 12 \text { (24) } \\
\text { months }\end{array}$ & $\begin{array}{r}756 \\
(927)\end{array}$ & $\begin{array}{c}29 \% \\
(36 \%)\end{array}$ \\
\hline 4 & Detailed ICD-10-GM diagnosis & all patients with COPD $\geq 40$ years with at least one documented ICD-10-GM code, that takes FEV1-values into account§ & 735 & $29 \%$ \\
\hline 5 & GOLD grade assigned & all patients with $C O P D \geq 40$ years with at least one GOLD-grade documented & \multicolumn{2}{|c|}{ not extractable } \\
\hline 6 & DMP-participation & $\begin{array}{l}\text { all patients with COPD } \geq 40 \text { years who are enrolled in the DMP for COPD and appear for their scheduled follow-up } \\
\text { appointments regularly }\end{array}$ & 776 & $30 \%$ \\
\hline 7 & Influenza vaccination & $\begin{array}{l}\text { all patients with COPD } \geq 40 \text { years with a billing code for influenza vaccination documented at least once within the last } \\
12 \text { (24) months }\end{array}$ & $\begin{array}{c}951 \\
(1116)\end{array}$ & $\begin{array}{c}37 \% \\
(43 \%)\end{array}$ \\
\hline 8 & Pneumococcal vaccination & $\begin{array}{l}\text { all patients with } C O P D \geq 40 \text { years with a billing code for pneumococcal vaccination documented at least once within the } \\
\text { last } 72 \text { months }\end{array}$ & 318 & $12 \%$ \\
\hline 9 & Smoking status & all patients with $C O P D \geq 40$ years with at least one documented smoking status within the last 12 (24) months & \multicolumn{2}{|c|}{ not extractable } \\
\hline 10 & Smoking cessation advice & $\begin{array}{l}\text { all smoking patients with COPD } \geq 40 \text { years with at least one documentation about given smoking cessation advice } \\
\text { within the last } 12(24) \text { months } \$\end{array}$ & \multicolumn{2}{|c|}{ not extractable } \\
\hline 11 & $\begin{array}{l}\text { Assessment of } \\
\text { inhaler technique }\end{array}$ & $\begin{array}{l}\text { all patients with } C O P D \geq 40 \text { years with at least one documentation about an assessment of their inhaler technique } \\
\text { within the last } 12(24) \text { months€ }\end{array}$ & \multicolumn{2}{|c|}{ not extractable } \\
\hline 12 & $\begin{array}{l}\text { Height/weight/ } \\
\text { BMI }\end{array}$ & $\begin{array}{l}\text { all patients with } C O P D \geq 40 \text { years with at least one documentation of either their body height and weight or their BMI } \\
\text { within the last } 12(24) \text { months }\end{array}$ & \multicolumn{2}{|c|}{ not extractable } \\
\hline 13 & mMRC or CAT & $\begin{array}{l}\text { all patients with COPD } \geq 40 \text { years with at least one documentation of a conducted COPD assessment (mMRC or CAT) in } \\
\text { the last } 12(24) \text { months }\end{array}$ & \multicolumn{2}{|c|}{ not extractable } \\
\hline 14 & Inhaled medications & all patients with $C O P D \geq 40$ years with at least one prescription of inhaled medications within the last 12 (24) months & $\begin{array}{c}1029 \\
(1288)\end{array}$ & $\begin{array}{c}40 \% \\
(50 \%)\end{array}$ \\
\hline 16 & ICS therapy & $\begin{array}{l}\text { all patients with COPD } \geq 40 \text { years with at least one prescription of an ICS (or another ICS-containing drug) in the last } 12 \\
\text { (24) months }\end{array}$ & $\begin{array}{r}599 \\
(736)\end{array}$ & $\begin{array}{c}23 \% \\
(28 \%)\end{array}$ \\
\hline 17 & $\begin{array}{l}\text { Patient medication scheme } \\
\text { provided }\end{array}$ & $\begin{array}{l}\text { all patients with COPD } \geq 40 \text { years for whom a patient medication scheme was newly documented or updated within the } \\
\text { last } 12(24) \text { months }\end{array}$ & $\begin{array}{r}1238 \\
(1238) \\
\end{array}$ & $\begin{array}{c}48 \% \\
(48 \%) \\
\end{array}$ \\
\hline 18 & Patient education program & all patients with $C O P D \geq 40$ years with a billing code for the patient education program documented & 9 & $<1 \%$ \\
\hline
\end{tabular}

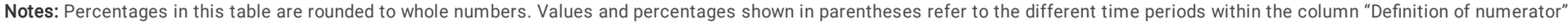
which are also presented in parentheses.

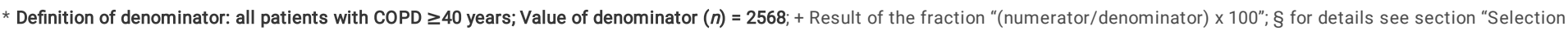
of quality indicators" and Table 2; \$ denominator for QI \#10 = all smoking patients with COPD $\geq 40$ years; $€$ denominator for QI \#11 = all patients with COPD $\geq 40$ years with inhaled medications; it must be noted that for QI \#16 a higher percentage does not correspond to a higher quality of care

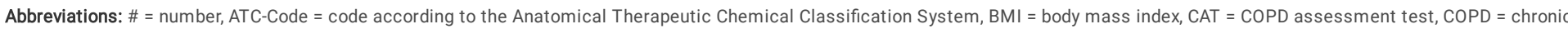

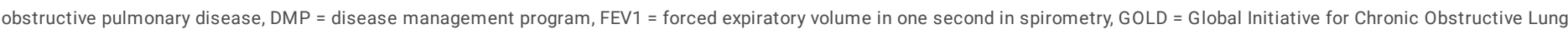

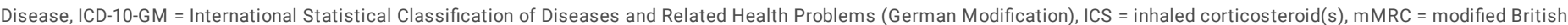
Medical Research Council, PBD = post-bronchodilator, QI = quality indicator 
Table 5: QI for COPD - alternative searches

\begin{tabular}{|c|c|c|c|c|}
\hline$\#$ & QI & Alternative definition for numerator (based on free-text/hybrid searches) $\$$ & $\begin{array}{c}\text { Value of } \\
\text { numerator\$s }\end{array}$ & Percentage+ \\
\hline 1 & $\begin{array}{l}\text { COPD confirmed by } \\
\text { PBD spirometry }\end{array}$ & $\mathrm{n} / \mathrm{a}$ & \multicolumn{2}{|c|}{ still not extractable } \\
\hline 5 & GOLD grade assigned & all patients with COPD $\geq 40$ years with at least one documentation of the term "GOLD" $\S$ & 55 & $2 \%$ \\
\hline 9 & Smoking status & $\begin{array}{l}\text { all patients with COPD } \geq 40 \text { years with at least one documentation of the German terms for "smok*", "tobacco", "cigar*", "pack years } \\
\text { or "PY" and/or the ICD-10-GM code "F17." within the last } 12(24) \text { months } \S\end{array}$ & $\begin{array}{c}1118 \\
(1144)\end{array}$ & $\begin{array}{l}44 \% \\
(45 \%)\end{array}$ \\
\hline 10 & $\begin{array}{l}\text { Smoking cessation } \\
\text { advice }\end{array}$ & $n / a$ & \multicolumn{2}{|c|}{ still not extractable } \\
\hline 11 & $\begin{array}{l}\text { Assessment of } \\
\text { inhaler technique }\end{array}$ & $\mathrm{n} / \mathrm{a}$ & \multicolumn{2}{|c|}{ still not extractable } \\
\hline 12 & $\begin{array}{l}\text { BMI/ } \\
\text { height and weight }\end{array}$ & $\begin{array}{l}\text { all patients with COPD } \geq 40 \text { years with at least one documented value of a BMI (or a combination of height and weight) within the } \\
\text { last } 12 \text { (24) months }\end{array}$ & $\begin{array}{c}156 \\
(256)\end{array}$ & $\begin{array}{c}6 \% \\
(10 \%)\end{array}$ \\
\hline
\end{tabular}

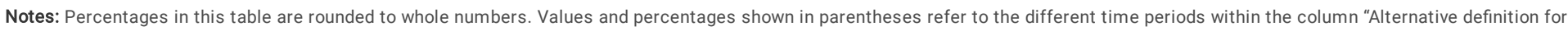
numerator" which are also presented in parentheses.

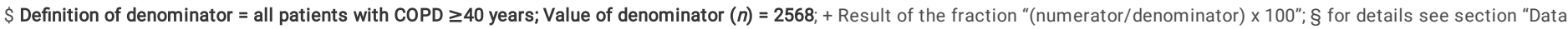
collection and analysis"

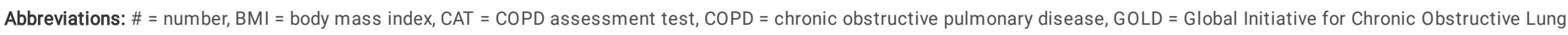

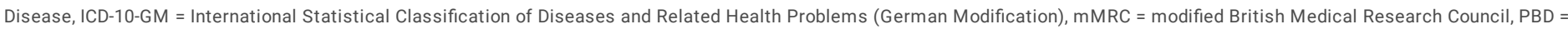
post-bronchodilator, QI = quality indicator 